\title{
Study of phytotoxic properties of sewage sludge stabilised by alkaline mediums
}

\author{
P. Samaras, C. A. Papadimitriou, E. Papastergiadis, A. Pappa \\ \& K. Gudulas \\ Department of Pollution Control Technologies, \\ Technological Educational Institute of Western Macedonia, \\ 50100 Kozani, Greece
}

\begin{abstract}
The aim of this work was the examination of the stabilization potential of sewage sludge by fly ash and lime and the investigation of the phytotoxic properties of the produced mixtures. About $0,5 \mathrm{~m}^{3}$ sewage sludge were mixed with the alkaline substances in various ratios and the products were stabilized for 3 months. Samples from each mixture were analyzed for the determination of their physicochemical content such as $\mathrm{pH}$, moisture, and nutrients. Stabilization of sewage sludge was achieved depending upon the concentration and the type of alkaline medium, due to the $\mathrm{pH}$ increase of the mixture; however, the alkaline addition resulted in the reduction of the nutrients content. Phytotoxicity effects were determined by the measurement of the corresponding inhibition effects of the produced mixtures on the seed germination and root length growth of three higher plants (one monocotyl and two dicotyls). Samples obtained from the early stages of stabilization process exhibited high inhibition on seed germination and root length growth; however, these effects were reduced for samples prepared at extended stabilization times.
\end{abstract}

Keywords: fly ash, lime, sewage sludge, stabilization, phytotoxicity.

\section{Introduction}

The improvement of sewage sludge management is an important issue during the preparation of an integrated wastewater management plan. Sewage sludge has been already utilized in agricultural and horticultural applications for several years as it represents an alternative source of nutrients for plant growth, and an 
efficient soil conditioner enhancing certain physical properties of soil [1]. However, sewage sludge may contain pathogenic organisms, a range of toxic metals and high amounts of soluble salts, which may affect the soil properties. Recently, increased attention was paid to the sludge stabilization process, aiming to minimize the mobility of heavy metals by using various additives, in accordance to more stringent regulations set in USA and European Union countries [2-5]. Lime is considered as one of the most common amendment material for sewage sludge stabilization, enhancing the agricultural benefits of sludge reuse and lowering the respective environmental risks [6]. This process has been proposed for the advanced treatment of sewage sludge in the relevant EU working document on sludge usage [2]. The high $\mathrm{pH}$ values of the limesludge mixture, maintained for extended periods, may result in the destruction of microbial communities and in the reduction of metal bioavailability [7]. However, the application of lime for the stabilization of sewage sludge depends upon a number of parameters, such as the availability of lime, the associated costs, the required period for stabilization etc.; thus, alternative materials, other than lime, should be considered for sludge stabilization.

Fly ash, i.e. the by-product from coal thermal power plants, may contain increased amounts of calcium and magnesium oxides depending upon the raw material, presenting, thus, highly alkaline values similar to lime. As a result, fly ash can be used as an alternative material for sludge stabilization with additional benefits, such as the reduced purchasing cost, and the minimization of fly ash disposal cost. In addition, this practice may be proved as an attractive management option for the combined reuse of two solid wastes, produced in vast amounts worldwide.

However, the application of alkaline stabilized sludge may cause severe problems ranging from crop nutrient deficiencies up to phytotoxicity. Nutrient imbalances may be attributed to the limited availability of various microelements to the plant, although their total concentration in the raw materials is often high; plant phytotoxicity may result from increased $\mathrm{pH}$ values [8]. As a result, land application of alkaline stabilized sludge requires the examination of their phytotoxic impacts, in addition to their stabilization potential.

The objectives of this work were the investigation of fly ash potential for the stabilization of sewage sludge, the study of the effect of different component ratios and ageing time on the process efficiency, and the examination of the produced mixtures environmental impacts by the evaluation of their phytotoxic properties.

\section{Materials and methods}

About $0,5 \mathrm{~m}^{3}$ of sludge piles were prepared by mixing fly ash and/or lime with sewage sludge in various ratios according to the conditions given in Table 1. Sewage sludge was obtained from the municipal wastewater treatment plant of Kozani in Northern Greece; fly ash was received from a lignite thermal power plant, while lime was offered by a Greek production company. Raw materials were mechanically mixed and were maintained for a period of 3 months for 
stabilization. Samples were withdrawn from each mixture at certain time periods and were analyzed for the determination of physicochemical $(\mathrm{pH}$, humidity, total nitrogen, phosphorus and potassium content), and microbiological (Total coliforms, E. Coli and Feacal coliforms) properties according to Standard Methods [9].

Table 1: $\quad$ Composition of sewage sludge/alkaline mixtures.

\begin{tabular}{cc}
\hline $\begin{array}{c}\text { Sample } \\
\text { Number }\end{array}$ & Composition \\
\hline 0 & Sewage sludge, control sample \\
1 & Sewage sludge with $10 \%$ lime (on a dry weight basis) \\
2 & Sewage sludge with $2 \%$ fly ash and $8 \%$ lime \\
3 & Sewage sludge with $10 \%$ fly ash \\
4 & Sewage sludge with $5 \%$ fly ash \\
5 & Sewage sludge with $15 \%$ fly ash \\
\hline
\end{tabular}

Phytotoxicity experiments were conducted by using three plant organisms, i.e. Alba sinapis, Shorgum saccharatum and Lepidium sativum (Phytotoxkit ${ }^{\circledR}$ supplied by Microbiotests). Ten seeds from each species were placed in flat shallow transparent test plates, composed of two compartments, the lower one able to maintain a reference OECD soil saturated to the water holding capacity. Test plates with the seeds were incubated for 3 days at $25^{\circ} \mathrm{C}$. The inhibition to seed germination and to the root growth was calculated by the following equation:

$$
I=\frac{A-B}{A} \times 100
$$

where:

$I=$ Inhibition $(\%)$

$A=$ mean seed germination or root length for the control soil

$B=$ mean seed germination or root length for the sample.

\section{Results and discussion}

Mixing of sewage sludge by the alkaline mediums resulted in the production of samples with increased $\mathrm{pH}$ values. The correlation of mixtures $\mathrm{pH}$ with the stabilization time is shown in Figure 1. The highest $\mathrm{pH}$ values were observed in mixtures of sludge with lime, reaching up to 12 , while lower $\mathrm{pH}$ values, around 9, were observed in mixtures with fly ash; $\mathrm{pH}$ values decreased by the stabilization time to about 8 , due to reactions taken place by the atmospheric carbon dioxide. However, the $\mathrm{pH}$ of the single sewage sludge was lower than 7 , which decreased by the stabilization time, due to organics acid production as a result of anaerobic decomposition. High $\mathrm{pH}$ values resulted to the reduction of microbial content of sludge mixtures. The content of Total Coliforms, Feacal Coliforms and E. Coli were reduced to negligible values, depending upon the alkaline medium and the stabilization time. The highest stabilization potential 
was achieved in samples produced by lime, or by the addition of high fly ash input, at prolonged stabilization times.

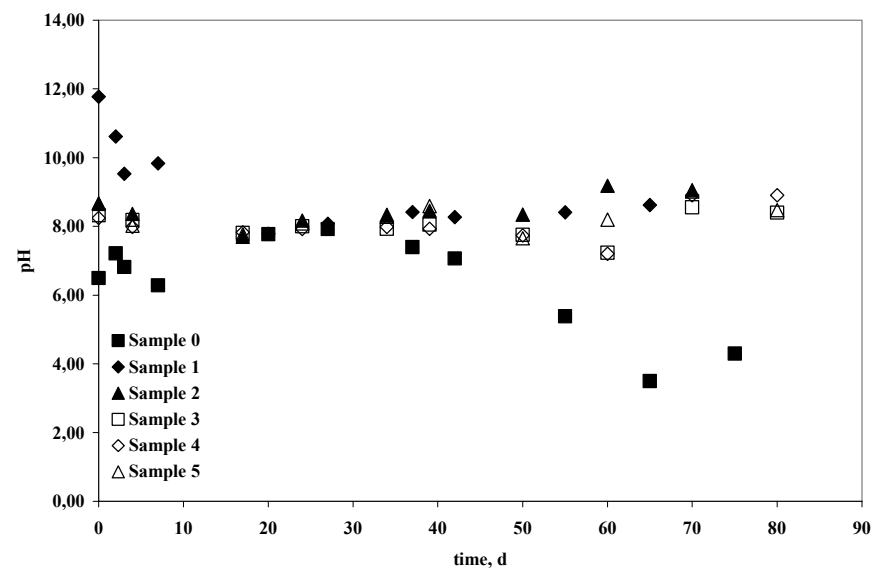

Figure 1: The correlation of sludge mixtures $\mathrm{pH}$, as a function of stabilization time.

An important issue in the land application of sludge mixtures is the concentration of nutrients and especially the content of potassium, total nitrogen and phosphorous. The concentration of these elements in the sludge mixtures is shown in Figure 2 as a function of stabilization time.

The highest contents of nutrients were measured in the single sludge sample; lower values were observed in the alkaline samples due to dilution. As shown, the three elements concentration followed the order: total nitrogen $>$ phosphorous $>$ potassium. However, during the ageing process, phosphorus was significantly depleted; after the $80^{\text {th }}$ day comparable concentrations of phosphorous and potassium were observed especially in the mixtures where fly ash was added, changing the balance of nutrients. The effects of the mixtures on the seed germination of Alba sinapis, Shorgum saccharatum and Lepidium sativum are shown in Figure 3 as a function of time. Although the same average seed germination inhibition values were calculated variations between the species, are attributed to their variable sensitivity. During the initial stages of stabilization, all mixtures exhibited strong inhibition to seed germination and root length growth of the test species, suggesting that the mixture properties were unsuitable for planting, possibly due to high $\mathrm{pH}$ values. However, germination of the test plants was observed after the $40^{\text {th }}$ day of planting. The single sewage sludge sample showed decreased effects on seed germination, even at extended times of stabilization. The samples with high fly ash content, produced at low stabilization times, showed increased inhibition effects that decreased by the reaction time; however, even after 90 days, stabilized samples presented seed germination inhibition exceeding 50\%. Lower 


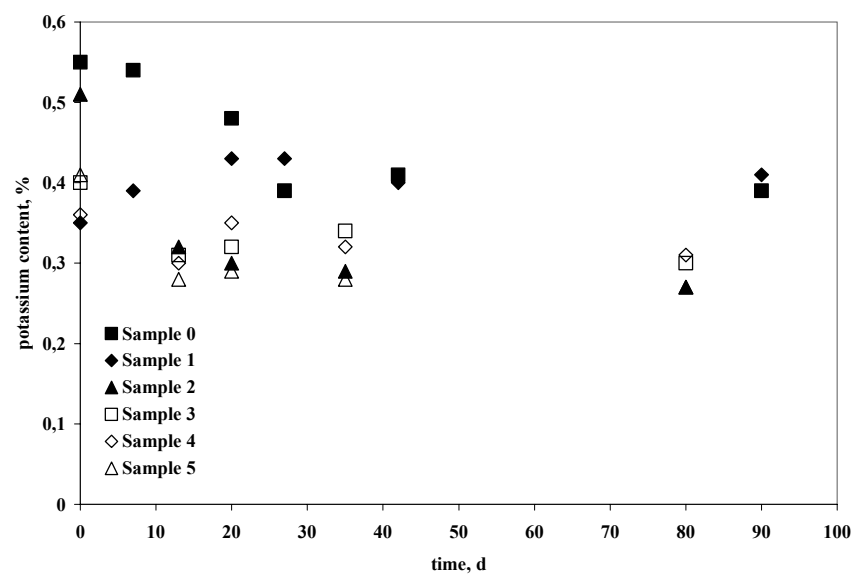

A

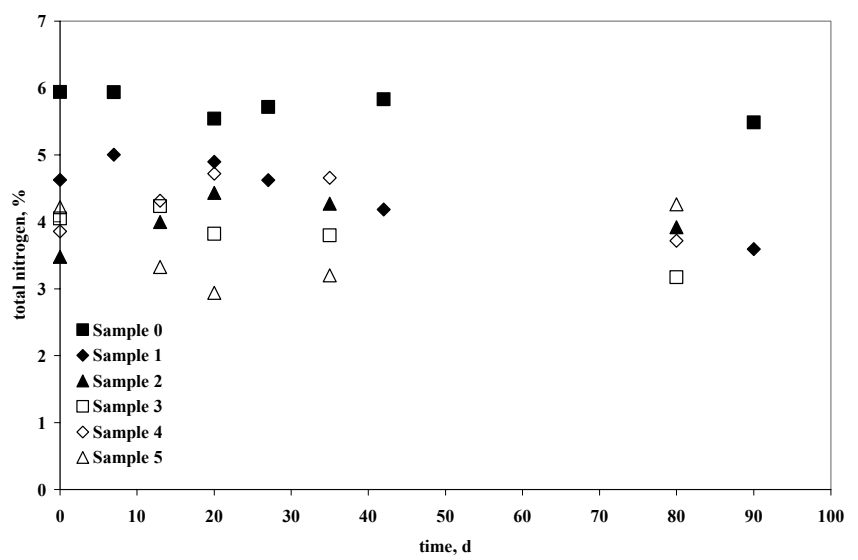

B

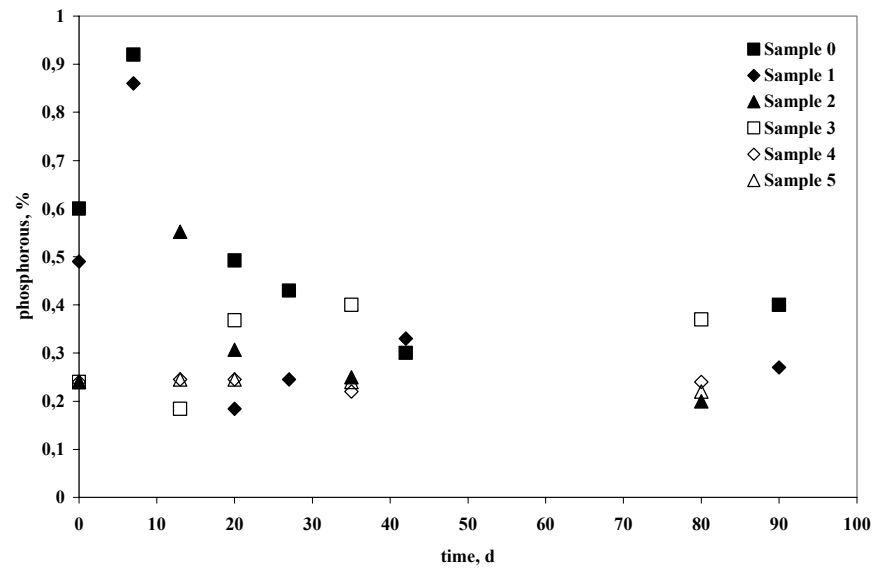

$\mathrm{C}$

Figure 2: $\quad$ The content of potassium (A), total nitrogen (B) and phosphorous (C) for the sludge mixtures as a function of time. 

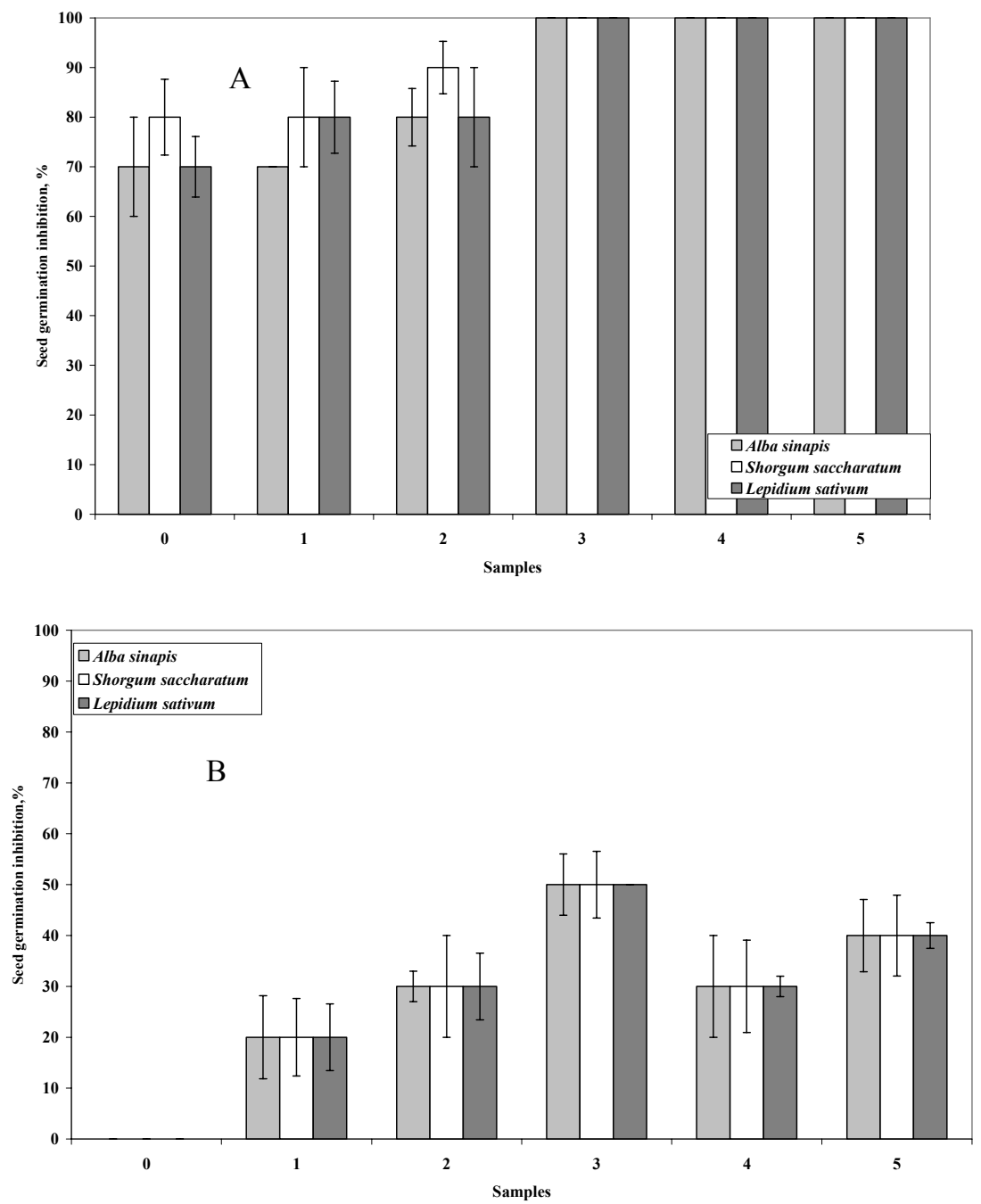

Figure 3: Effects of various mixtures to seed germination of Alba sinapis, Shorgum saccharatum and Lepidium sativum at 40(A) and 90(B) days of ageing process.

inhibition effects were observed for the samples with lower content of fly ash. Similar to seed germination effects, the plantation on the sludge mixtures was strongly inhibited; root length growth ranged from 50 to $80 \%$ for the sewage sludge sample and from $70-100 \%$ for the samples with $15 \%$ fly ash. The samples with high sludge and low fly ash content presented a decline of the inhibition rate on root elongation by the stabilization time; low inhibition effects were observed at stabilization times exceeding two months. 
The corresponding effects on seed germination and root length growth may be attributed to the release of metals elements from the mixture components to the soil environment and their consequent uptake by the plants [10]. It has been found that especially copper may have a strong toxic effect to the plants, mainly on the growth of the roots [11]. The increased inhibition on root length growth may be attributed to the imbalanced nutrients of the mixtures. It has been reported that for the grain shorghum a proper balance for $\mathrm{N} / \mathrm{P} / \mathrm{K}$ should be 9.0/1/4.4 [8]. The ratio between $\mathrm{P} / \mathrm{K}$ in the samples produced during this work was around $1 / 1$, indicating potassium deficiency, while total nitrogen was exceptionally high. In addition to dilution, nutrients availability is affected by the presence of various metals in fly ash mixtures: calcium and magnesium may contribute to phosphorous chemical precipitation, reducing its plant availability $[12,13]$.

In conclusion, the mixing of sewage sludge by fly ash or lime resulted in the stabilization of produced materials, due to the establishment of high $\mathrm{pH}$ values. However, the mixing with alkaline agents reduced the content of nutrients and affected their availability to plants. Stabilized sludge mixtures presented a strong inhibition effect to root elongation and seed germination of test plants, due to high $\mathrm{pH}$ values and nutrients deficiency. However, phytotoxicity of produced samples was reduced by the stabilization time, implicating that the proposed method could be used as an alternative practice for the effective land application of sewage sludge, by the implementation of appropriate stabilization conditions.

\section{Acknowledgements}

This work was financially supported by the Technical Enterprise MESOGEIOS ATEE. The authors would like to acknowledge the contribution of the personnel of DIADYMA S.A. for the preparation of the sludge mixtures.

\section{References}

[1] T.J. Logan, B.J. Harrison, Physical characteristics of alkaline stabilized sewage sludge (N-Viro soil) and their effects on soil physical properties, J. Environ. Qual. 24 (1995) 153-164.

[2] L. Spinosa, From sludge to resources through biosolids, Water Sci. Tech. 50 (2004) 1-9.

[3] M. Fang, J.W.C. Wong, K.K. Ma, M.H. Wong, Co-composting of sewage sludge and coal fly ash: nutrient transformations, Biores. Tech. 67 (1999) $19-24$.

[4] A.A. Zorpas, T. Constantinides, A.G. Vlyssides, I. Haralambous, M. Loizidou, Heavy metal uptake by natural zeolite and metals partitioning in sewage sludge compost, Biores.Tech. 72 (2000) 113-119.

[5] K.Y. Chiang, S.D. Yoi, H.N. Lin, K.S. Wang, Stabilization of heavy metals in sewage sludge composting process, Water Sci. Tech. 44 (2001) 95-100.

[6] J.W.C. Wong, A. Selvam, Speciation of heavy metals during cocomposting of sewage sludge with lime, Chemosphere 63 (2006) 980-986. 
[7] J. Akrivos, D. Mamais, K. Katsara, A. Andreadakis, Agricultural utilization of lime treated sewage sludge, Water Sci. Tech. 42 (2000) 203-210.

[8] A.W. Schumman and M.E. Sumner, Formulation of environmentally sound waste mixtures for land application, Water, Air and Soil Pollution 152 (2004) 195-217

[9] American Public Health Association, Standard Methods for the Examination of Water and Wastewater, 17th ed., Washington, DC, 1989.

[10] A. Fuentes, M. Lloréns, J. Sáez, M.I. Aguilar, A. Belén, B. Pérez-Marín, J.F. Ortuño, V.F. Meseguer, Ecotoxicity, phytotoxicity and extractability of heavy metals from different stabilised sewage sludges, Environ. Poll. 134 (2006) 355-360.

[11] A. Fargasova, Root growth inhibition, photosynthetic pigments production, and metal accumulation in Sinapis alba as the parameters for trace metalse determination, Bull. Environ. Contam. Toxicol. 61 (1998) 762-769.

[12] D.C Su and J.W.C. Wong , The growth of corn seedlings in alkaline coal fly ash stabilized sewage sludge, Water, Air and Soil Pollution 133 (2002) $1-13$

[13] J. Pichtel, M. Anderson, Trace metal bioavailability in municipal solid waste and sewage sludge composts, Biores. Tech. 60 (1997) 223-229. 